\title{
Discurso sobre o sujeito executivo na mídia: encapsulamentos anafóricos e catafóricos que não encapsulam apenas partes do texto
}

\section{Discourse on the executive subject in the media: anaphoric and cataphoric encapsulations that do not encapsulate only parts of the text}

DOI: $10.46814 /$ lajdv2n6-025

Recebimento dos originais: 01/09/2020

Aceitação para publicação: 30/10/2020

\section{Alessandro Alves da Silva}

Mestre em Letras (Estudos Linguísticos: Estudos do Texto e do Discurso) pela Universidade Estadual de Maringá-PR. Professor de Projetos Extracurriculares na Faculdade de Tecnologia Alfa de Umuarama. Rua Desembargador Antonio Franco Ferreira da Costa, 3678, Zona 1, CEP 87501200, Umuarama - PR.

E-mail: alessandroalvesdasilva@hotmail.com

\section{Pedro Navarro}

Professor do Departamento de Letras da UEM e do Programa de Pós-Graduação em Letras

(Mestrado e Doutorado) desta mesma universidade. Pesquisador líder do Grupo de Estudos

Foucaultianos (GEF/UEM/CNPq). Universidade Estadual de Maringá, Centro de Ciências Humanas, Letras e Artes - CCH, Bloco G-34, Av. Colombo, 5.790, Maringá - PR, CEP: 87020900.

E-mail: plnavarro@uol.com.br

\section{RESUMO}

O presente artigo tem como objetivos: 1) analisar algumas denominações em relação ao sujeito executivo presentes na versão online da revista Você $S / A$, buscando mostrar alguns dos saberes e dos poderes que vão se formando em relação a este sujeito; 2) mostrar que tais dispositivos atualizam-se em práticas discursivas midiáticas que, pela escolha lexical, posicionam os indivíduos (os sujeitos executivos) como sujeitos competitivos, empreendedores de si mesmos, conhecedores de si mesmos, comprometidos, interessados, obstinados, realizadores e motivadores. O suporte de análise é essencialmente discursivo e se vale, principalmente, do método arqueogenealógico de análise de discursos proposto pelo filósofo francês Michel Foucault. Tal método "busca compreender o sentido a partir da análise da rede interdiscursiva em que a série se encontra, da relação, portanto, que um enunciado mantém com os outros" (NAVARRO, 2008, p. 63). Paralelamente ao método arqueogenealógico de análise de discursos foram utilizados alguns aportes teóricos e linguísticos como ferramentas auxiliares para a análise da função enunciativa que se exerce, constituindo sentidos sobre esse sujeito executivo: 1) "encapsulamentos" (CONTE, 2003); 2) "denominações" (CAMACHO; HATTNHER; GONÇALVES, 2008) e (MARIANI, 1998) e 3) "equação linguística" (SOARES, 2006).

Palavras-Chave: Análise do Discurso, Michel Foucault, Equação Linguística, Encapsulamentos, Sujeito Executivo, Denominações. 


\section{ABSTRACT}

This article aims to: 1) analyze some denominations in relation to the executive subject present in the online version of the magazine Você S / A, seeking to show some of the knowledge and powers that are being formed in relation to this subject; 2) show that such devices are updated in media discursive practices that, by lexical choice, position individuals (executive subjects) as competitive subjects, entrepreneurs of themselves, self-aware, committed, interested, obstinate, achievers and motivators. The analysis support is essentially discursive and uses mainly the archeogenealogical method of discourse analysis proposed by the French philosopher Michel Foucault. This method "seeks to understand the meaning from the analysis of the interdiscursive network in which the series is found, from the relationship, therefore, that a statement maintains with others" (NAVARRO, 2008, p. 63). Alongside the archeogenealogical method of discourse analysis, some theoretical and linguistic contributions were used as auxiliary tools for the analysis of the enunciative function that is exercised, constituting meanings about this executive subject: 1) "encapsulations" (CONTE, 2003); 2) "denominations" (CAMACHO; HATTNHER; GONÇALVES, 2008) and (MARIANI, 1998) and 3) "linguistic equation" (SOARES, 2006).

Keywords: Discourse Analysis, Michel Foucault, Linguistic Equation, Encapsulations, Executive Subject, Denominations.

\section{INTRODUÇÃO}

O senso comum (principalmente em se tratando do público leitor), de forma quase que geral, tem a impressão de que o discurso da imprensa escrita (em especial dos jornais e revistas) fundamenta-se ou organiza-se a partir dos mitos de verdade, objetividade, neutralidade e imparcialidade (MARIANI, 2005) e da linguagem como, exclusivamente, um instrumento de transmissão de informações. No imaginário de grande parte do público leitor de jornais e revistas —se foi publicado é porque é verdade/é importantell (Cf. SOARES, 2006 e NAVARRO, 2008).

Se retomarmos as reflexões dos pensadores sofistas gregos, nós entenderemos que para eles não existia —all verdade (uma única verdade), mas várias verdades que eles encontravam pelos locais por onde passavam e pelas diferentes pessoas com as quais conversavam.

Ao se fazer um paralelo disso com as diversas Análises de Discursos francesas (tanto de orientação mais pêcheutiana quanto de orientação mais foucaultiana), perceberemos que —all verdade pode ser entendida como —uma versão da realidade a partir de recortes ideológicos\| - é o que dizem muitos analistas de discursos adeptos das teses pêcheutianas - ou como um -efeito de verdade\| dentro de determinados solos epistemológicos - como dizem muitos analistas de discursos adeptos às ideias foucaultianas.

Não se trata aqui, nestes breves e simples exemplos, de querer defender um método de análise de discursos em função de outro, mas sim de mostrar o quanto o conceito de verdade é relativo em ambos. 
Por conta destes mitos, os textos publicados nas revistas semanais ou nos jornais diários são tomados como verdade absoluta por uma grande maioria dos leitores. Para comprovarmos esta asserção, basta lermos as cartas de leitores que agradecem ao jornal ou revista pela -prestação de serviçoll por meio da -boa informaçãol (verdadeira, objetiva, imparcial e neutra).

O discurso midiático é —uma prática discursiva identitáriall (NAVARRO, 2008) na qual se retomam ou se ressignificam mitos do passado, constroem-se memórias e identidades do presente e do futuro, etc. É uma prática discursiva que atua na (des)construção de identidades, ou seja, constroi realidades e institucionaliza comportamentos.

Estas práticas discursivas midiáticas exercem poderes em relação ao sujeito executivo, de modo a ir subjetivando e constituindo saberes sobre este sujeito. A identidade do sujeito executivo vai sendo constituída por meio destes discursos que atravessam e constituem sentidos sobre ele.

Diante deste contexto, o presente artigo tem como objetivo analisar algumas denominações em relação ao sujeito executivo presentes na versão online da revista Você $S / A$, buscando mostrar alguns dos saberes e dos poderes que vão se formando em relação a este sujeito.

Para tanto, além de alguns conceitos do campo de pesquisa doravante denominado Análise do Discurso de orientação francesa (AD), usaremos também o conceito de Equação Linguística (SOARES, 2006) e a obra intitulada Gramática do Português Culto Falado no Brasil (ILARI \& NEVES, 2008), no que tange aos nomes e verbos, que servirão como instrumentos de análise que nos dão ancoragem linguística para tratarmos de fatos de discurso - no caso deste breve artigo, como se produz a identidade do sujeito executivo - de modo a salientar que essas relações entre aspecto linguístico e fenômeno discursivo são de suma importância.

\section{MATERIAIS E MÉTODOS}

O trabalho de investigação desta pesquisa está sendo desenvolvido por meio de montagem de bancos de dados das edições online da revista Você S/A, publicadas entre os anos de 2008 e 2011.

Para trabalhar com este corpus de estudo está sendo utilizado o método arqueogenealógico de análise de discursos proposto pelo filósofo francês Michel Foucault.

Este método arqueogenealógico de estudo dos discursos -busca compreender o sentido a partir da análise da rede interdiscursiva em que a série se encontra, da relação, portanto, que um enunciado mantém com os outros\| (NAVARRO, 2008, p. 63).

Também estão sendo utilizadas obras de pesquisadores que tratam da questão linguística relacionada a fenômenos extralinguísticos. São eles: Soares (2006) e Ilari \& Neves (2008). 


\section{O SUJEITO EXECUTIVO SENDO DENOMINADO}

Conforme foi dito acima, no método arqueogenealógico de análise de discursos o analista de discursos tentará fazer uma apreensão das regularidades discursivas existentes nas relações que os enunciados estabelecem entre si, nas relações entre grupos de enunciados no interdiscurso e nas relações entre estes enunciados e acontecimentos discursivos, culturais, políticos e históricos.

Ao trabalhar com as relações de saber e poder Michel Foucault mostrará que —o poder não tem uma relação direta com o Estado, uma vez que ele se exerce em níveis e em pontos diferentes da sociedade, configurando uma rede complexa de micropoderes\| (NAVARRO, 2008, p. 63). O poder não é, na acepção de Foucault, algo exclusivamente negativo: ele produz saberes e induz ao desejo.

Quando ao enunciado, Foucault concebe-o como a menor unidade do discurso que o analista de discursos recorta do arquivo. Foucault concebe o enunciado como uma função que abarca: 1) um princípio de diferenciação que engloba o objeto do qual o discurso fala (o sujeito executivo, a sua carreira, etc); 2) uma posição de sujeito, considerado em termos de modalidades enunciativas; 3) um domínio associado, que diz respeito às relações entre os enunciados e os demais grupos de enunciados, de modo que este elemento da função enunciativa aponte para as noções de memória discursiva e interdiscurso. Estas funções desempenhadas pelo enunciado podem ser percebidas nas denominações sobre o sujeito executivo, que o caracterizam, que o rotulam, que o classificam.

As denominações (substantivos, adjetivos, expressões, nominalizações, encapsulamentos, locuções adjetivas, etc) compõem grandes blocos de produção de sentidos (SOARES, 2006) em relação ao que elas se referem.

\footnotetext{
Semanticamente, além de denominar, o substantivo referencia, função [...] pela qual se refere às coisas, aqui entendidas como qualquer entidade do mundo extralinguístico, real ou imaginário. Um outro modo de entender a referenciação dos substantivos é analisar seu funcionamento circunscrito ao universo textual, ou seja, não mais tratálo como objeto do mundo, mas como objeto do discurso. [...] o tratamento conjunto de substantivos e adjetivos sob o rótulo nome remonta a uma longa tradição nos estudos da linguagem. $\mathrm{O}$ que parece justificar esse tratamento unificado é o fato de, nas línguas clássicas (o grego e o latim), as duas classes compartilharem propriedades mórficas, como flexão de gênero, número e caso, sendo possível a distinção entre ambas somente em termos funcionais (CAMACHO; HATTNHER; GONÇALVES, 2008, p. 21-22, grifos nossos).
}

Esse aporte teórico e linguístico é um dos componentes para a análise da função enunciativa que se exerce, constituindo sentidos sobre esse sujeito executivo. Sob um enfoque discursivo é possível perceber que ao denominar as pessoas vão criando sítios de significância ou regiões discursivas (ORLANDI, 1996) em relação ao que é denominado.

Conforme pondera Mariani, 
O processo de denominação não está na ordem da língua ou das coisas, mas organiza-se na ordem do discurso, o qual, relembrando mais uma vez, consiste na relação entre o linguístico e o histórico-social, ou entre linguagem e exterioridade (MARIANI, 1998, grifos nossos).

As denominações, por representarem uma posição discursiva em relação ao que se denomina, dão visibilidade ao sujeito que fala no interior dos enunciados e às formações discursivas a partir das quais emergem os enunciados.

Sobre o conceito de formação discursiva (FD) - ao mesmo tempo tão problemático e tão necessário à Análise do Discurso francesa (AD) -, Foucault (2008) pondera que:

No caso em que se puder descrever, entre um certo número de enunciados, semelhante sistema de dispersão, e no caso em que entre os objetos, os tipos de enunciação, os conceitos, as escolhas temáticas, se puder definir uma regularidade (uma ordem, correlações, posições e funcionamentos, transformações), diremos, por convenção, que se trata de uma formação discursiva - evitando, assim, palavras demasiado carregadas de condições e consequências, inadequadas, aliás, para designar semelhante dispersão, tais como "ciência", ou "ideologia", ou "teoria", ou "domínio de objetividade (FOUCAULT, 2008, p. 48).

Veremos aqui, neste momento, que as formações discursivas a partir das quais emergem os enunciados sobre o sujeito executivo constituem uma regularidade em meio às dispersões de vários outros enunciados. É de suma importância destacar que no método arqueogenealógico de análise de discursos a análise vai do enunciado à formação discursiva.

Em outras palavras, o que se está apresentando, neste momento da pesquisa, como regular nestas formações discursivas são os efeitos de sentido de que o sujeito executivo é um sujeito comprometido, interessado, obstinado e realizador: um sujeito empreendedor de si mesmo. Foucault nos mostra, por exemplo, que o simples fato do sujeito querer mudar o seu corpo mostra que ele é um empreendedor de si mesmo que se vale dos seus cuidados de si.

Os sentidos sobre o sujeito executivo - sobre o que é ser executivo na contemporaneidade - partem, nos textos que estão sendo analisados nesta pesquisa, de formações discursivas (FDs) médicas, econômicas, psicológicas, jurídicas, etc. de modo a constituir saberes e poderes em relação a este sujeito.

Como dito anteriormente, está sendo utilizado aqui o conceito de Equação Linguística - que nos dá ancoragem linguística para tratarmos de fatos de discurso - (sujeito executivo = ousadia + posições de liderança + fluente em inglês), explicitado por Soares (2006):

A equação lingüística [...] aparece como uma evidência, como se ela estivesse sempre jálá. E qualquer interpretação fora dessa equação é do campo do impossível de dizer, pelo menos atualmente. Chamo de equação lingüística [...] a equivalência de sentidos entre duas ou mais expressões produzidas e recorrentes no interior de uma determinada 
formação discursiva a partir de certas condições de produção de sentido (SOARES, 2006, p. 64, grifos nossos).

Como diz Soares (2006), o conceito de equação linguística vai abarcar a sua relação com a formação discursiva na qual ocorrem estas expressões. Ao afirmar isso, o pesquisador nos alerta para o fato de que os sentidos — se colam\| por meio de processos discursivos. Se $\mathrm{X}$ significa $\mathrm{X}$ numa determinada formação discursiva, em determinadas condições de produção, em outra formação discursiva $X$ pode significar $Y$.

Este conceito tem íntima relação com a enunciação e a escolha lexical - escolher determinadas palavras e expressões em detrimento de outras -, por englobar, dentre outras coisas, quem enuncia, em que situação enuncia, para quem enuncia e a partir de qual posição- sujeito enuncia.

Temos abaixo alguns fragmentos de textos verbais sobre o sujeito executivo que fazem parte do nosso corpus. Após estes fragmentos seguem as discussões e reflexões deste artigo.

\subsection{O PEDREIRO QUE CONTRATOU O EXECUTIVO}

A história de ousadia do profissional que recusou 13 propostas de emprego e um salário $40 \%$ maior para trabalhar numa empresa desconhecida Renata Avediani, de Porto Velho (RO) / 05/01/2010

Em maio do ano passado, o engenheiro civil (1) mineiro Marcelo Miranda, de 32 anos, voltava de uma temporada de quase dois anos de estudos na Universidade Stanford, na Califórnia, onde fazia mestrado em administração e negócios, para um ciclo de entrevistas de emprego no Brasil. Como queria regressar ao país após a conclusão do curso, ele vinha mantendo contato com amigos e ex-colegas de trabalho.

[...] Apesar da pouca idade, Marcelo tem um currículo respeitável. Do tipo que faz brilhar os olhos de qualquer profissional de recursos humanos. Ele é formado por uma boa escola, a Universidade Federal de Minas Gerais, e tem vivência no exterior, estudou recentemente nos Estados Unidos e passou quatro anos no Iraque, onde seu pai esteve a trabalho. É fluente em inglês e já ocupou posições de liderança bastante desafiadoras pelas empresas por onde passou - Andrade Gutierrez, MRV e Caenge, obtendo bons resultados em todas elas.

[...] O engenheiro (2) abriu mão do status de executivo na maior vitrine profissional do país para se juntar a um empreendedor visionário (3), que criou um método de construção inovador, usando moldes, como se fossem formas de bolo, para construir casas pré-fabricadas de 36 a 120 metros quadrados. O menor módulo custa 40000 reais. O maior sai por 250000 reais. O sistema de produção se assemelha ao de uma linha de montagem de carros. Com esse sistema, a BS Construtora, fundada em 1994, fabrica atualmente 19 casas por dia. A decisão de Marcelo de se juntar a Sidnei é emblemática, pois quebra alguns paradigmas.

Disponível em: < http://vocesa.abril.com.br/desenvolva-sua- carreira/materia/pedreirocontratou-executivo-523644.shtml >. Acesso em 10 jul. 2011.

\subsection{SUCESSO É GENÉTICO?}

As escolhas profissionais de homens e mulheres podem ser determinadas pela genética, segundo o livro O Paradoxo Sexual, de Susan Pinker

Elisa Tozzi 06/04/2010 
A psicóloga canadense (1) Susan Pinker, autora do recém-lançado $O$ Paradoxo Sexual (Editora BestSeller), coloca pimenta na tradicional discussão da guerra dos sexos. Para ela, a disparidade entre os gêneros pode ser explicada a partir de fatores biológicos: por ter hormônios e genes diferentes, homens e mulheres fazem escolhas diferentes na carreira. De acordo com o livro, se elas não chegam ao topo não é apenas por preconceito ou falta de oportunidades oferecidas pela empresa.

O organismo, afirma Susan, também influi no destino profissional. "A genética pode orientar as decisões de carreira de qualquer pessoa", diz.

-Um jogador de basquete pode ter decidido entrar nessa profissão por causa de sua estrutura corporal. Minha proposta é usar a biologia como ponto de partida para analisar também as diferenças de gêneroll, escreve Susan.

Munida de pesquisas científicas e anos de experiência clínica, a psicóloga (2) afirma que, por terem conexões cerebrais e hormônios distintos, os homens são mais propensos à rivalidade e a atividades que envolvam sistemas padronizados.

Disponível em: < http://vocesa.abril.com.br/desenvolva-suacarreira/materia/sucesso-genetico-546392.shtml >. Acesso em 10 jul. 2011.

Apresentamos aqui (brevemente) algumas equações linguísticas que constituem sentidos sobre o sujeito executivo coletadas neste nosso corpus.

Dentre tantas outras construções não mencionadas aqui e que funcionam parafrasticamente em relação a estas, destacamos, para este trabalho, estas construções: ser executivo $=$ - ousadia + currículo respeitável + vivência no exterior + empreendedor visionário + estudou recentemente nos Estados Unidos + é fluente em inglês e já ocupou posições de liderança bastante desafiadoras pelas empresas por onde passou + as escolhas profissionais de homens e mulheres podem ser determinadas pela genética, segundo o livro O Paradoxo Sexual, de Susan Pinker + a mudança na economia afeta de maneira diferente cada profissional: veja o que fazer para atravessar esse período de turbulênciall (presentes na revista Você S/A entre os anos de 2008 e 2011).

Como nós podemos ver nestas construções destacadas acima, a identidade desse sujeito executivo vai sendo construída mediante saberes vindos do exterior (trata-se aqui da exterioridade constitutiva de todo discurso) e que vão organizando os sentidos do que é ser executivo hoje. O que vemos em funcionamento é um poder que classifica, enquadra, separa e rotula esse sujeito. Esse efeito se materializa no momento em que o enunciador qualifica (denomina) esse sujeito.

O sintagma nominal —o sujeito executivol é acompanhado por vários elementos linguísticos (adjetivações, predicativos do sujeito, etc) que o complementam. O uso de verbos no pretérito perfeito geralmente dá a ideia de uma ação acabada, finalizada com êxito, tal qual se espera, nestas formações discursivas, de um executivo (oсирои posições de liderança). 
Além disso, nas expressões nominais marcadas em negrito nos textos acima podemos perceber a ocorrência do que Conte (2003) chama de encapsulamentos. Conte (2003) diz que o encapsulamento é um tipo de anáfora lexical que funciona como —um recurso coesivo pelo qual um sintagma nominal funciona como uma paráfrase resumidora para uma porção precedente do textoll.

O que é possível observar nos textos acima é que além de retomar o que foi dito no texto, estes encapsulamentos atuam como elementos catafóricos que ajudam a introduzir novas informações nos textos. É possível perceber, nos textos acima, que estes encapsulamentos não só dão orientações argumentativas que participam da organização de processos discursivos, mas que também orientam (ajudam a direcionar) a leitura do leitor. Estes encapsulamentos também são responsáveis pela coesão e pela coerência textuais, de modo a conectar as partes do texto entre si.

Em outras palavras, numa perspectiva discursiva, entendemos que estes encapsulamentos, por assim dizer, encapsulam todo um conjunto de enunciados presentes ou não nos textos acima: são aspectos linguísticos relacionados a fenômenos discursivos que encapsulam todo um saber que se projeta sobre este sujeito executivo nestes enunciados.

Destacamos também a ocorrência de verbos que se comportam semanticamente como verbos de estado. Assim, em -é fluente em inglêsl o verbo ser (é), neste enunciado, indica um estado do sujeito e não uma ação praticada pelo sujeito.

Ser fluente em inglês é, de forma quase que geral, tido como um estado comum a grande parte dos executivos. Considerando-se a globalização, espera-se, nestas formações discursivas que constituem e atravessam sentidos sobre o sujeito executivo, que a grande maioria dos sujeitos executivos seja fluente em inglês.

Ao observarmos mais atentamente o funcionamento discursivo destas denominações dentro de determinadas formações discursivas, que são o que Foucault (2008) chama de regularidades em meio à dispersão, podemos perceber que o sujeito executivo é um sujeito ativo, competitivo, obstinado e realizador que pratica ações, e que, ao mesmo tempo, é muito bom em algo: é fluente em inglês.

Estas denominações complementam, descrevem e adjetivam o que é ser executivo. É importante frisar, retomando a citação acima, que estas denominações consistem na relação entre o linguístico e o extralinguístico, ou seja, entre o linguístico e o histórico-social.

Em outras palavras: estas denominações estão na ordem dos discursos que se materializam nestas denominações e que constituem e atravessam sentidos sobre este sujeito executivo.

Denominar, portanto, não é um ato neutro, mas representa uma posição discursiva em relação ao que é denominado. Denominar é uma das formas pelas quais se exerce uma prática 
discursiva identitária que se projeta sobre o executivo, dizendo para ele quem ele é ou deve ser, uma vez que isso envolve a posição-sujeito de quem denomina.

No caso do sujeito executivo, temos várias posições-sujeito de quem denomina os sujeitos executivos. Temos as posições-sujeito da área da psicologia, da biologia, da medicina, da economia, da linguagem, do direito, dentre outras.

O que é regularidade na dispersão (FOUCAULT, 2008) em meio a tudo o que se disse (e ainda de diz) sobre o sujeito executivo nos enunciados e séries enunciativas presentes no nosso corpus, constitui estes dizeres cristalizados (e outros que vão se cristalizando por meio de processos discursivos) sobre o sujeito executivo.

É possível perceber que estas denominações atuam como processos discursivos que se constituem, por meio de práticas discursivas midiáticas, em -formas de poder que instauram uma nova ordem de saber\| (NAVARRO, 2006; 2008) sobre essas identidades em construção do sujeito executivo.

Como diz Navarro (2008), estas formas de poder produzem saberes em relação ao sujeito executivo, ao ponto de pensarmos que o sujeito executivo só pode ser $\mathrm{X}$ e nunca Y. Só pode ser, discursivamente, pelo menos atualmente neste momento de observação do corpus, um sujeito adjetivado como comprometido, obstinado, realizador, ousado, etc.

É como se neste momento não houvesse espaço, discursivamente falando, para se enunciar de outras posições que digam que é possível o sujeito executivo ser um executivo, mas que não está nem aí para a empresa onde trabalha, que só quer ganhar o seu salário, etc. Enunciados como estes ainda não foram encontrados no corpus em estudo. Funcionam como não ditos em relação ao que se diz.

Foucault nos ensina que o poder também produz saberes, mas que este poder não é uma espécie de entidade centralizada: nós nos movemos (vivemos nossas vidas), de acordo com Foucault, em meio a vários dispositivos de poder. Não há um poder, mas vários poderes.

Quando, por exemplo, a mídia televisiva chama alguém considerado especialista em recursos humanos para dar dicas de como ter êxito na carreira profissional vemos, muitas vezes, este especialista dizendo que o executivo deve falar -corretamentel (dicotomia certo/errado do senso comum), vestir-se adequadamente, mover-se adequadamente, controlar seus pensamentos e sentimentos, etc.

Neste caso do sujeito executivo, ele vai se tornando objeto dos discursos oriundos de diversas formações discursivas: medicina, economia, administração, etc. São discursos que dizem o que é ser executivo e o que se espera de um executivo. São saberes e poderes que vão se formando em relação a este sujeito. 
É difícil não observarmos a relação de interdiscursividade entre o antigo preceito délfico do —conhece-te a ti mesmoll e os enunciados sobre o sujeito executivo na mídia brasileira contemporânea.

É como se todos estes enunciados tivessem uma relação interdiscursiva com o enunciado reitor — conhece-te a ti mesmoll. Os enunciados sobre o sujeito executivo posicionam-no, de forma quase que geral, como um sujeito centrado e totalmente controlador de tudo o que diz e pensa: como um sujeito que se conhece e que é empreendedor de si mesmo.

Autoconhecimento e autocontrole são características deste sujeito: um sujeito que sabe tomar decisões, que não tem dúvidas sobre quem é e sobre o que faz, que tem metas a cumprir, que é objetivo, etc.

Estas práticas discursivas midiáticas colocam estes indivíduos (estes sujeitos executivos) como sujeitos competitivos. Elas determinam quem pode falar sobre o sujeito executivo e as posições que este sujeito pode ocupar, de modo a exercer uma espécie de governamentabilidade em relação a este sujeito executivo. Ele vai sendo subjetivado e vai se tornando objeto dos discursos.

\section{CONSIDERAÇÕES FINAIS}

Os resultados têm demonstrado, nestes primeiros meses da pesquisa e nestas breves análises, que o sujeito executivo é (nos textos que compõem o corpus) um sujeito controlador de tudo o que diz e pensa: um sujeito empreendedor de si mesmo.

Além disso, percebe-se, neste momento da pesquisa, que vários saberes e poderes atravessam e constituem sentidos sobre o sujeito executivo: medicina, psicologia, economia, linguagem, etc. e que estas práticas discursivas midiáticas, por meio destas denominações, que representam uma posição discursiva em relação ao que é denominado, têm papel crucial neste processo discursivo, tendo em vista, dentre outras coisas, a sua importância na argumentação textual.

Além disso, como vimos, o léxico que se usa (comprometido ao invés de descomprometido) para denominar este sujeito, em sua relação com a história, produz determinados efeitos de sentido e ecoa determinadas memórias discursivas e não outras.

Como podemos observar o sujeito executivo é um sujeito polifônico, isto é, portador de várias vozes que enunciam sobre ele. Ele é composto de várias denominações e carrega consigo vários saberes - saberes produzidos por poderes - que o constituem enquanto sujeito.

O sujeito executivo é, portanto, pela ótica do campo de pesquisa denominado Análise do Discurso francesa (AD), um sujeito dividido, descentrado, em meio aos vários saberes e poderes que o constituem. 
Por meio deste processo discursivo instaurado pelas práticas discursivas midiáticas alguns sentidos (comprometido, interessado, obstinado, realizador, etc) e não outros (descomprometido, desinteressado, etc) vão sendo sedimentados em relação a este sujeito, de modo a pensarmos que o sujeito executivo só pode ser, na ordem dos discursos que se materializam sobre ele, X e nunca Y.

Finalmente, é importante destacar que há algumas questões que não foram respondidas adequadamente neste artigo. Uma delas está ligada às relações complexas entre aspecto linguístico e fenômeno discursivo. Outra questão está ligada aos saberes e poderes que constituem e atravessam sentidos sobre o sujeito executivo em suas relações entre os processos de objetivação e subjetivação deste sujeito.

Por enquanto, estas questões ficam em aberto, de modo a nos convidarem a continuarmos pesquisando sobre estas complexas temáticas.

\section{REFERÊNCIAS}

CONTE, Maria-Elisabeth. Encapsulamento anafórico. In: CAVALCANTE, Mônica Magalhães et al. (orgs.). Referenciação. São Paulo: Contexto, 2003 (p.177-190).

FOUCAULT, Michel. A arqueologia do saber. Rio de Janeiro: Forense Universitária, 2008.

ILARI, Rodolfo; NEVES, Maria Helena de Moura. (Orgs.). Gramática do Português Culto Falado no Brasil. V. II. Classes de Palavras e Processos de Construção. Campinas: Ed. da Unicamp, 2008.

MARIANI, Bethânia Correia. (1998). O PCB e a imprensa - os comunistas no imaginário dos jornais 1922-1989. Rio de Janeiro: Revan.

Para que(m) serve a psicanálise na imprensa? (2005). Disponível em: < http://www.geocities.com/gt_ad/bethania.doc >. Acesso em: 26 jun. 2009.

NAVARRO, Pedro. Estudos do texto e do discurso: mapeando conceitos e métodos. São Carlos: Claraluz, 2006.

(Discurso, História e Memória: Contribuições de Michel Foucault ao Estudo da Mídia) In Estudos do Texto e do Discurso. Interfaces entre Língua(gens), Identidade e Memória. Tasso, Ismara (org.), Ed.: Claraluz (ed.). São Carlos-SP, 2008, Vol.2, p. 59-74.

ORLANDI, Eni. Interpretação: autoria, leitura e feitos do trabalho simbólico. Petrópolis: Vozes, 1996.

SOARES, Alexandre Sebastião Ferrari. A Homossexualidade e a AIDS no Imaginário de Revistas Semanais (1985-1990). 2006. 235f. Tese (Doutorado em Letras) - Universidade Federal Fluminense, Niterói, 2006. 